\title{
RpoN2- and FliA-regulated fliTX is indispensible for flagellar motility and virulence in Xanthomonas oryzae pv. oryzae
}

\author{
Chao Yu, Huamin Chen, Fang Tian, Fenghuan Yang and Chenyang He*
}

\begin{abstract}
Background: Bacterial blight of rice caused by Xanthomonas oryzae pv. oryzae (Xoo) is one of the most important crop diseases in the world. More insights into the mechanistic regulation of bacterial pathogenesis will help us identify novel molecular targets for developing effective disease control strategies. A large flagellar gene cluster is regulated under a three-tiered hierarchy by $\sigma^{54}$ factor RpoN2 and its activator FleQ, and $\sigma^{28}$ factor FliA. A hypothetical protein gene fliTX is located upstream of rpoN2, however, how it is regulated and how it is related to bacterial behaviors remain to be elucidated.

Results: Sequence alignment analysis indicated that FliTX in Xoo is less well conserved compared with FliT proteins in Escherichia coli, Salmonella typhimurium, and Pseudomonas fluorescens. Co-transcription of fliTX with a cytosolic chaperone gene fliS and an atypical PilZ-domain gene flgZ in an operon was up-regulated by RpoN2/FleQ and FliA. Significantly shorter filament length and impaired swimming motility were observed in $\triangle$ fliTX compared with those in the wildtype strain. $\triangle$ fliTX also demonstrated reduced disease lesion length and in planta growth in rice, attenuated ability of induction of hypersensitive response (HR) in nonhost tobacco, and down-regulation of type III secretion system (T3SS)-related genes. In trans expression of fliTX gene in $\triangle$ fliTX restored these phenotypes to near wild-type levels.
\end{abstract}

Conclusions: This study demonstrates that RpoN2- and FliA-regulated fliTX is indispensible for flagellar motility and virulence and provides more insights into mechanistic regulation of T3SS expression in Xoo.

Keywords: Xanthomonas oryzae pv. oryzae, Flagellar motility, Pathogenicity, Induction of hypersensitive response, T3SS

\section{Background}

Bacterial leaf blight caused by Xanthomonas oryzae pv. oryzae (Xoo) is a major bacterial disease of rice in Asian countries, which can lead to $20 \%-50 \%$ yield loss in rice production [1]. Xoo has been used as a model pathogen to study the molecular mechanism of bacterial pathogenesis in monocotyledonous plants $[2,3]$. Now, we have learned that Xoo produces multiple virulence factors, such as exopolysaccharide (EPS), extracellular enzymes, adhesins, and the type III secretion system (T3SS) and its effectors [1, 4, 5]. HrpG and HrpX are the two master regulators to control the expression of hrp genes and type III effector genes [6]. Moreover, some other regulators controlling the expression of these

\footnotetext{
* Correspondence: hechenyang@caas.cn

State Key Laboratory for Biology of Plant Diseases and Insect Pests, Institute

of Plant Protection, Chinese Academy of Agricultural Sciences, Beijing 100193, China
}

virulence factors have also been identified [6-8]. One of the important regulators is alternative sigma factor $\sigma^{54}$ encoded by rpoN2 $[9,10]$. Deletion of rpoN2 significantly reduces virulence and flagellar motility, yet how exactly RpoN2 regulates these virulence phenotypes in Xoo remains unknown [10].

The flagellum is the main motor organ in bacteria, which helps bacteria move toward favorable conditions and become infectious [11-13]. The flagellum consists of three parts, the basal body, the hook, and the filament. The regulatory network of flagellar gene transcription is quite complicated and fascinating. In Escherichia coli and Salmonella typhimurium, over 650 genes involved in flagellum assembly are organized into a hierarchy of three classes [14-16]. The FlhDC encoded by the class I gene $f l h D C$ is the master regulator and controls the transcription of class II genes [17]. The class II gene products include most of flagellum structural components and alternative sigma factor FliA 
$\left(\sigma^{28}\right)$. FliA regulates the transcription of class III genes, which encode the hook-associated proteins FlgK and FlgL, the anti- $\sigma^{28}$ factor FlgM, the flagellar cap FliD, the flagellin FliC and other proteins involving in chemosensory signal transduction $[18,19]$. The flagellar gene cluster of Pseudomonas aeruginosa has a four-tiered hierarchy of transcriptional regulation. Class I genes encode the $\sigma^{54}$ factor RpoN and $\sigma^{54}$-dependent transcriptional activator FleQ. Class II genes include the two-component system fleSR and the $\sigma^{28}$ factor fliA. The transcription of fleSR and fliA are regulated by RpoN and FleQ. Class III genes are regulated by FleR and are necessary for completion of the basal-body hook structure. Class IV genes are transcribed by FliA and encode the flagellin and some chemotaxis proteins $[20,21]$.

FliT is a key chaperone in the flagellar assembly and operation, which interacts with several flagellar proteins, including the filament-cap FliD, the export apparatus components FliI (ATPase), FliJ and FlhA, and the master regulator FlhDC [22-27]. FliT binds to the cognate substrates to not only prevent them from degradation and aggregation in the cytoplasm, but also efficiently transfer them to the export apparatus [28]. The structural analysis has showed that FliT adopts an auto-inhibited conformation, in which both the substrate- and FlhAbinding sites are occluded. Formation of FliT-substrate complex activates its binding to FlhA and thus targeting of the complex to the export gate [29]. In addition, FliT acts as a negative regulator of flagellar regulon and inhibits the binding of FlhDC to the promoter DNA [27, 30]. Interestingly, deletion of fliT does not affect the swimming ability in S. typhimurium, but significantly reduces motility properties in P. fluorescens [23, 31]. Moreover, disruption of $f l i T$ induces the expression of Salmonella pathogenicity island 1 (SPI1) genes, implying the potential role of FliT in bacterial virulence [32].

Our previous study has showed that over 60 contiguous flagellar genes forming a large gene cluster in Xoo PXO99 ${ }^{\mathrm{A}}$ encode proteins with various functions, including structural components, protein export apparatus, regulatory factors, post-translational modification enzymes, and chemotaxis proteins [10]. These genes were tightly regulated under a three-tiered hierarchy by $\sigma^{54}$ factor RpoN2, and transcriptional activator FleQ, and $\sigma^{28}$ factor FliA. Interestingly, a hypothetical protein gene PXO_06168, named as fliTX, has been revealed upstream of rpoN2 and downstream of fliS, which is very similar location of the fliT genes in the genome of S. typhimurium and P. fluorescens. However, how fliTX is regulated and how it is related to bacterial behaviors, such as flagellar motility and virulence, remain to be elucidated.

In this study, we characterized the regulation and biological functions of fliTX. Promoter activities and quantitative real-time polymerase chain reaction (qRT-PCR) assays demonstrated that the transcription of fliTX was up-regulated by RpoN2, FleQ and FliA. In frame deletion of fliTX led to significant changes in flagellar motility, pathogenicity on rice, hypersensitivity on tobacco, and T3SS-related gene transcription, suggesting that FliTX plays key roles in controlling flagellar motility and virulence in Xoo.

\section{Results}

\section{Identification, deletion and complementation of fliTX}

Our previous study showed that there is a flagellar regulon containing over 60 contiguous genes in the genome of Xoo strain PXO99 ${ }^{\mathrm{A}}$, which are regulated by RpoN2 and FleQ [10]. Upstream of rpoN2, there were five genes encoding a filament cap protein FliD (PXO_06166), a cytosolic chaperone FliS (PXO_06167), a hypothetical protein FliTX (PXO_06168), a non-canonical PilZ-domain protein FlgZ (PXO_06169), and a DNA-binding response regulator (PXO_06170) (Fig. 1a). The intergenic distances of neighboring genes are $150 \mathrm{bp}, 9 \mathrm{bp},-1 \mathrm{bp}$, and $71 \mathrm{bp}$, respectively. Reverse transcription polymerase chain reaction (RT-PCR) analysis was performed to determine whether these five genes form an operon. The fragments containing junctions of fliS-fliTX and fliTX-flgZ were obtained using the Xoo cDNA as the template (Fig. 1a), indicating that fliS, fliTX and flgZ are co-transcribed in an operon. Sequence alignment analysis indicated that FliTX was less well conserved compared with FliT proteins in Escherichia coli, Salmonella typhimurium, and Pseudomonas fluorescens (Fig. 1b). To further identify the role of FliTX in Xoo, an in-frame deletion mutant $\triangle f l i T X$ and its complementary strain $\triangle f l i T X-C$ were generated as described in the Materials and Methods. DNA sequencing analysis showed that the corresponding region of fliTX was completely deleted in $\triangle f l i T X$.

\section{fliTX is transcriptionally up-regulated by RpoN2, FleQ and FliA}

To identify whether and how fliTX is regulated in Xoo, the promoter activities of the fliS-fliTX-FlgZ operon were examined by measuring $\beta$-galactosidase activity of the fliSplacZ fusion in $\triangle r p o N 2, \Delta f l e Q, \Delta f l i A$, and the relevant complementary strains. $\beta$-galactosidase activity of fliSp-lacZ was significantly reduced in $\triangle r p o N 2, \Delta f l e Q$, and $\triangle f l i A$ compared with that in the wild type, and restored in the relevant complementary strains (Fig. 2a). qRT-PCR analysis showed that transcripts of fliS, fliTX, and FlgZ were dramatically decreased in $\triangle r p o N 2, \Delta f l e Q$, and $\triangle$ fliA compared with that in wild type (Fig. 2b), indicating that the transcription of the fliS-fliTX-FlgZ operon was regulated by RpoN2, FleQ, and FliA. Consistent with our previous report [10], the transcription of $f l i A$ was also significantly decreased in $\triangle r p o N 2$ and $\triangle f l e Q$ (Fig. 2b). These results strongly suggest that RpoN2/FleQ regulate the transcription of the fliSfliTX-FlgZ operon via FliA in Xoo. 


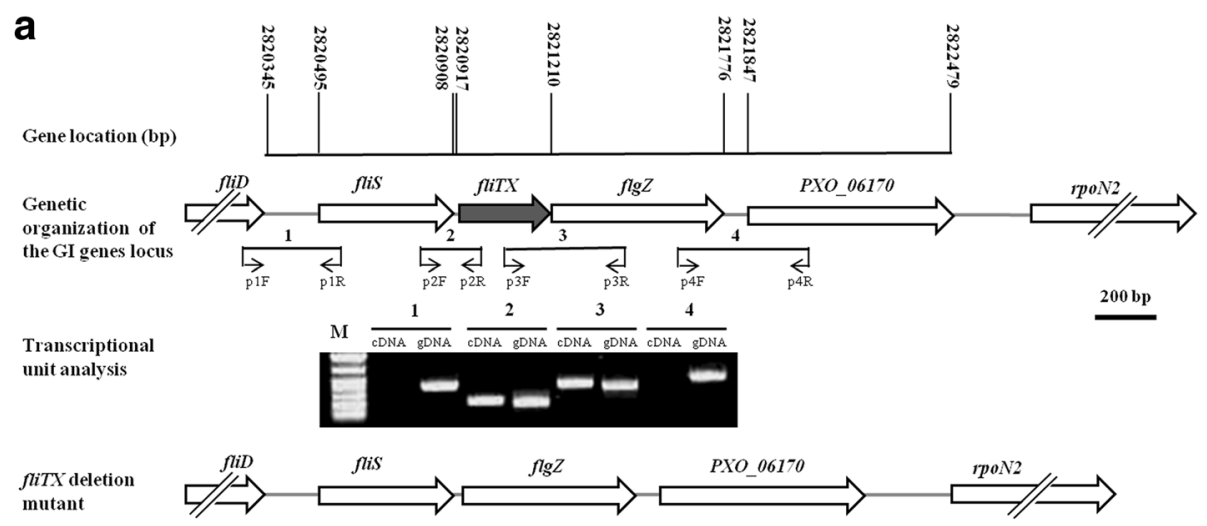

b

\begin{tabular}{|c|c|c|}
\hline oli & 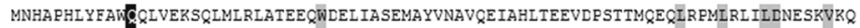 & 80 \\
\hline S. typhimurium & TSTVEF INRW & 80 \\
\hline P. fluorescens & ......MSLVICRIECTRDALVDALAERNWEAIGQIDLACRSCMELVISESQVD $\ldots \ldots$ EAALRINIEELLGVYRCIIE & 68 \\
\hline$X$ oryzae & 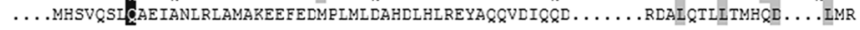 & 65 \\
\hline E. coli & 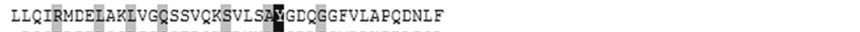 & 121 \\
\hline S. typhimurium & LQQRIDELSSIIGQQSTRCKSINND YGRISGMLIVPDAPGA & 121 \\
\hline P. fluorescens & AATGERQAIVDEM QCIHQAQ & 98 \\
\hline X. oryzae & MMRERCRKILEIIRACRTSSSASRAYARVGRI $\ldots \ldots \ldots$ & 97 \\
\hline
\end{tabular}

Fig. 1 Bioinformatics analysis of fliTX in Xanthomonas oryzae pv. oryzae. a Schematic diagram of the region including fliTX in the genome of PXO99A. Open arrows indicate length, location and orientation of the ORFs. The short lines below the arrows indicate the location and length of RT-PCR products. The lower element shows the RT-PCR analysis of RNA isolated from PXO99A. RT-dependent amplification of DNA fragments suggested that the flis, fliTX and $f l g Z$ were transcribed in one operon. The lowest element shows the fliTX was in-frame deleted in $\triangle$ fliTX. $\mathbf{b}$ Sequence alignment of FliTX was performed using DNAMAN software. The amino acid sequences of FliT were obtained from the National Center for Biotechnology Information (NCBI) website. E. coli: Escherichia coli strain MG1655; S. typhimurium Salmonella typhimurium LT2 strain; P. fluorescens: Pseudomonas fluorescens strain F113; X. oryzae: Xanthomonas oryzae pv. oryzae strain $\mathrm{PXO99}{ }^{A}$. The amino acid residues highlighted with black means the homology level is $100 \%$

\section{FliTX is required for flagellar motility and filament production}

Since fliTX is located within the flagellar regulon, the function of FliTX in flagellar filament assembly and flagellum-dependent motility was investigated. The swimming ability of $\triangle$ fliTX was detected on the $0.25 \%$ agar semisolid plates. Compared with the wild type strain, $\triangle$ fliTX showed a much smaller swimming zone, and the defect was restored to near wild-type level in the complementary strain containing a plasmid to express the full length of fliTX in trans (Fig. 3a). To further determine whether deletion of fliTX affected the flagellar biogenesis in Xoo, the single-polar flagellum of various Xoo strains were observed by transmission electron microscope (TEM). The average length of the flagellum on $\triangle$ fliTX was significantly shorter than that on the wild type, and it was recovered to wild-type level in the complementary strain (Fig. 3b). These results indicate that FliTX is necessary for flagellar biogenesis and motility in Xoo.

\section{$\Delta$ fliTX shows reduced pathogenicity and bacterial growth in rice}

To demonstrate the function of fliTX in virulence, the pathogenicity of various Xoo strains on susceptible rice cultivar IR24 was tested by the leaf clipping method, and lesion lengths were measured 14 days post inoculation. Compared with the wild type, $\triangle$ fliTX caused much shorter disease lesion, which were restored in the complementary strain (Fig. 4a and b). Measuring bacterial population in the diseased leaves of rice showed that deletion of fliTX significantly led to reduced bacterial population in rice leaves, but complementation with fliTX in trans restored the bacterial growth in planta to near wild-type levels (Fig. 4c). These findings reveal that FliTX is required for virulence of Xoo in rice.

\section{$\Delta$ fliTX is impaired in the ability to elicit hypersensitive response (HR) in tobacco}

To unveil the role of FliTX in Xoo when interacting with nonhost plants, HR-inducing ability of Xoo strains on tobacco leaves was tested. Wild type strain induced the typical programmed cell death due to the hypersensitive responses (HR) in the non-host tobacco plants. In contrast, $\triangle$ fliTX completely lost such an ability to elicit HR, while the complementary strain caused a similar phenotype as the wild type strain (Fig. 5a). We then hypothesized that FliTX protein might be able to elicit HR. To test it, the recombinant protein FliTX-His 6 was first expressed in E. coli strain BL21 and extracted from the 


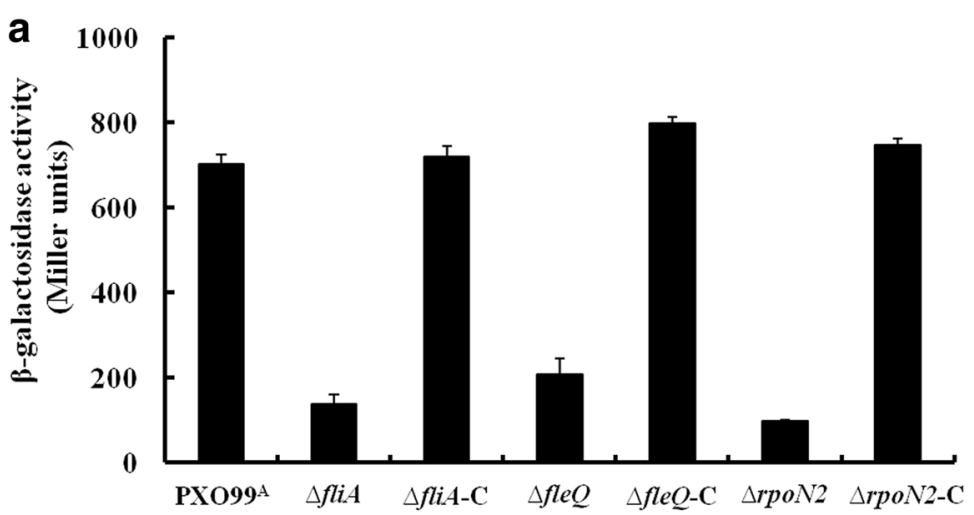

b

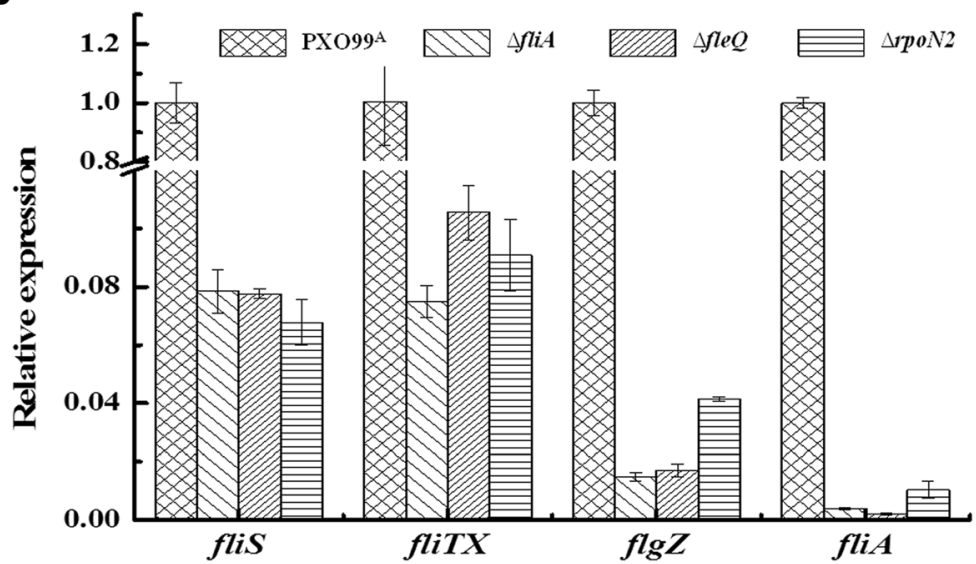

Fig. 2 Regulation of fliTX transcription in Xanthomonas oryzae pv. oryzae. a $\beta$-galactosidase activity assay. Activities of the flis promoter in Xoo strains were detected. The experiments were repeated three times, independently. $\mathbf{b}$ qRT-PCR analysis of genes in flis operon and fliA in Xoo strains. The data represents the relative expression level of genes in $\mathrm{PXO99} A, \triangle f l i A, \triangle f l e Q$ and $\triangle r p o N 2$. The error bar represents standard deviations from three biological repeats
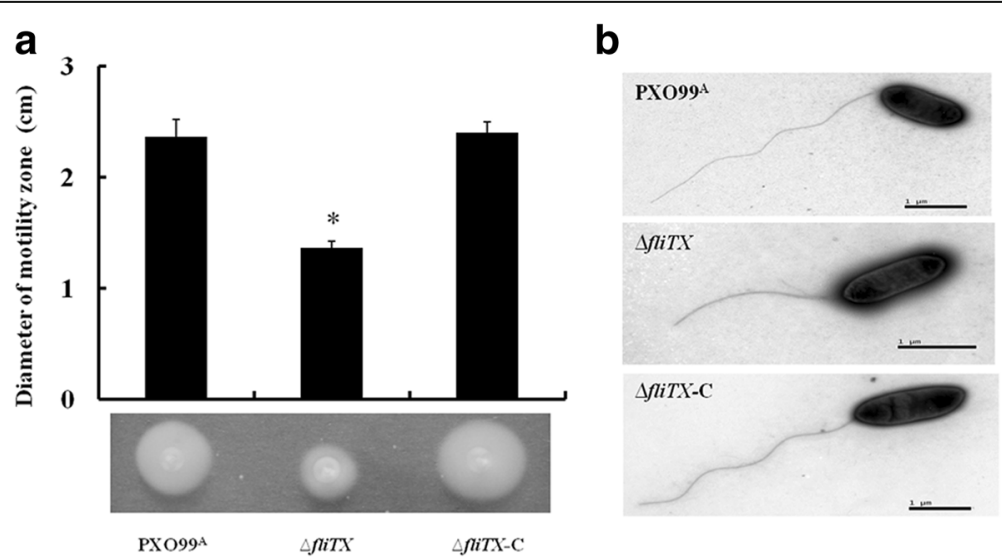

Fig. 3 Flagellar motility and filament production of Xanthomonas oryzae pv. oryzae strains. a Assay of swimming motility for PXO99 ${ }^{A}, \triangle f l i T X$ and $\triangle$ fliTX-C strains. The swimming zones are recorded after bacterial growth for 4 days on the semisolid plates at $28^{\circ} \mathrm{C}$. Error bars indicate stand deviation. Statistical significance is presented by asterisk $\left(P<0.05\right.$, Student's $t$ test). b Observation of filament for PXO99 ${ }^{A}, \triangle f l i T X$ and $\triangle f l i T X-C$ strains using transmission electron microscopy 
a
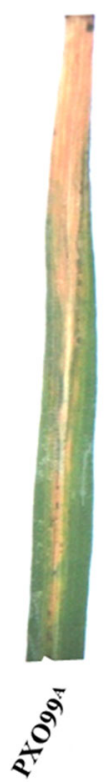
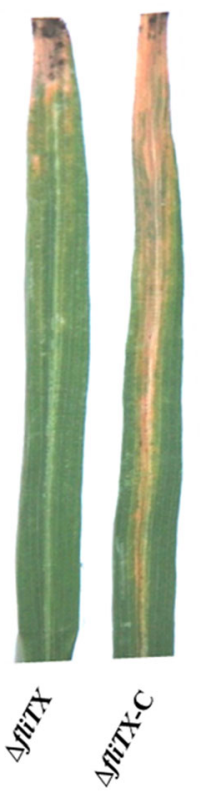
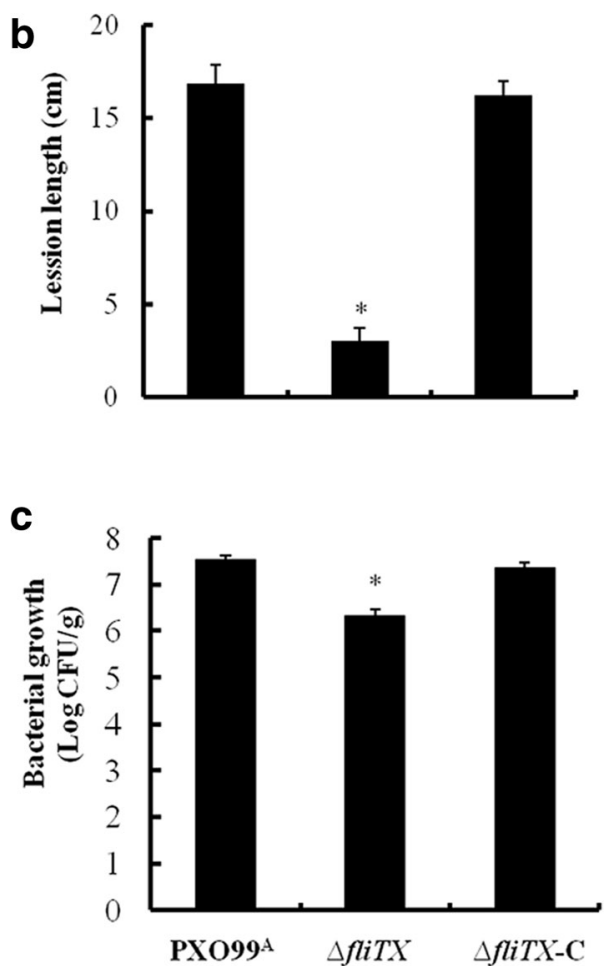

Fig. 4 Virulence of Xanthomonas oryzae pv. oryzae strains in rice. a PXO99A $\triangle{ }^{A} f l i T X$ and $\triangle f l i T X-C$ strains were inoculated into 6-week-old rice leaves by using the leaf-clipping method. The disease symptoms were observed at 14 days post-inoculation. $\mathbf{b}$ The lesion lengths were recorded from 10 inoculated leaves for every strain. c Bacterial numbers in the top $20 \mathrm{~cm}$ of each lesion leaf were scored. Data represent the mean and standard deviations of three independent experiments, and the asterisk above the bars denote statistically significant differences $(P<0.05$, Student's $t$ test $)$
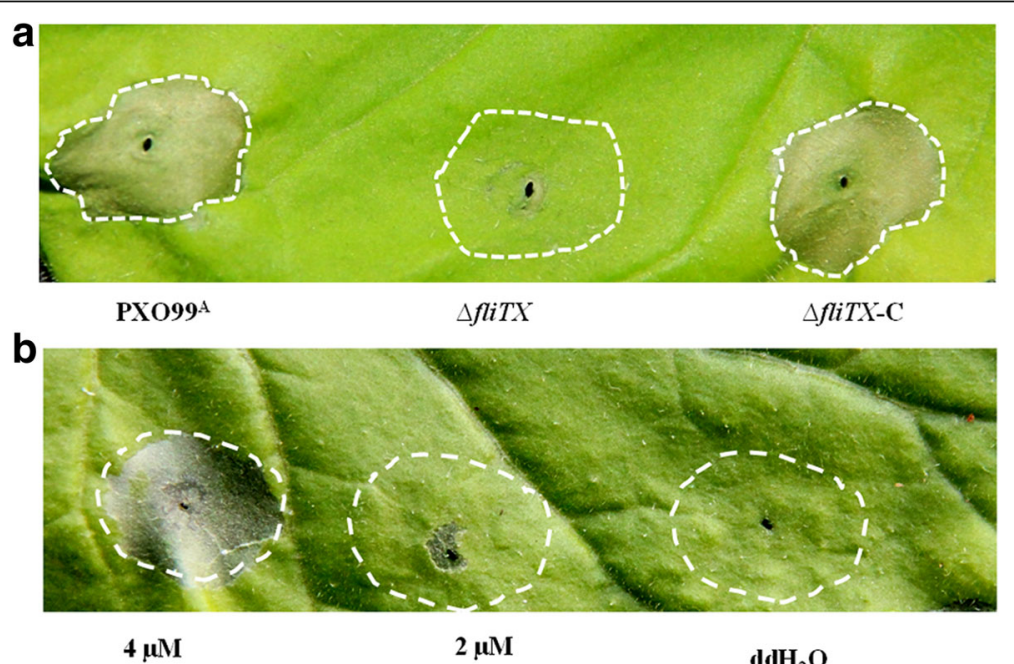

\section{FliTX}

Fig. 5 Hypersensitive cell death in tobacco induced by Xanthomonas oryzae pv. oryzae strains and FliTX protein. Cell suspensions of Xoo strains at $\mathrm{OD}_{600}$ of 0.1 (a) or recombinant FliTX protein (b) were infiltrated onto 6-week-old tobacco leaves. The $\mathrm{ddH}_{2} \mathrm{O}$ was used as control. The HR symptoms were detected and photographed at $24 \mathrm{~h}$ post-inoculation. At least four independent experiments were performed with similar results 
soluble fraction by using pre-equilibrated Ni2_resin. SDS-PAGE analysis demonstrated that FliTX-His ${ }_{6}$ was about $14 \mathrm{KDa}$ in size (Additional file 1: Figure S1). Then, the purified protein was infiltrated into tobacco leaves at two different concentrations. HR in tobacco was strongly induced when FliTX-His ${ }_{6}$ was applied at the concentration of $4 \mu \mathrm{M}$, while no $\mathrm{HR}$ was observed when the concentration was reduced to $2 \mu \mathrm{M}$ (Fig. 5b). The negative control of sterilized double-distilled water $\left(\mathrm{ddH}_{2} \mathrm{O}\right)$ did not cause HR either. These observations demonstrate that FliTX protein plays an important role in Xoo to elicit HR in nonhost tobacco.

\section{$\Delta$ fliTX was attenuated in T3SS-related gene expression}

The HR-inducing ability on nonhost and pathogenicity on host (Hrp) is closely related to T3SS in pathogenic bacteria [33, 34]. To understand the function of FliTX in T3SS in Xoo, transcripts of T3SS-related hrp genes were measured through qRT-PCR analysis. Compared with that in the wild type, transcription levels of $h r p G, h r p X$, $h r p E$ and $h p a 1$ were significantly decreased in $\triangle f l i T X$, and restored near to wild-type level in the complementary strain (Fig. 6a). Moreover, promoter activities of $h r p G, h r p X$ and $h p a 1$ revealed through flow cytometry analysis were dramatically reduced in $\triangle f l i T X$ compared with that of the wild type. All promoter activities were restored to wild-type levels in the complementary strain (Fig. 6b). Since HrpG controls the transcript of other hrp genes via regulating $h r p X$ expression in Xanthomonas [35], these results suggest that FliTX positively regulates the expression of T3SS in Xoo through the master regulator HrpG.

\section{Discussion}

In the current study, we identified a novel flagellar gene fliTX, determined its expression patterns, and assessed its functions in motility and virulence on rice through bioinformatics and genetic analysis. We demonstrated that the transcription of fliTX was positively regulated by RpoN2/FleQ and FliA. We also revealed that fliTX was indispensible for bacterial phenotypes, including flagellar motility, pathogenicity in rice, induction of HR in tobacco, and T3SS-related gene expression. Therefore, our identification of FliTX provides more insights into mechanistic regulation of motility and virulence in Xoo.

An over 60 contiguous gene containing cluster has been shown to putatively encode flagellar proteins with various functions, including structural components, protein export apparatus, regulatory factors, post-translational modification enzymes/proteins, and chemotaxis proteins in Xoo $[9,10]$. The flagellar assembly and operation are tightly regulated under a three-tiered hierarchy by RpoN2/FleQ and FliA [10]. Based on the gene location and transcription feature, we found that fliTX was transcribed in the fliS-fliTX-flgZ operon regulated by RpoN2/FleQ and FliA (Figs.1 and 2). This is quite different from the fliD-fliS-fliT operon in other pathogenic bacteria including E. coli and S. typhimurium [36, 37]. The significantly reduced transcripts of fliA in $\triangle$ rpoN2 and $\triangle f l e Q$ (Fig. 2b) suggest that regulation of transcription of the fliS-fliTX-flgZ operon by RpoN2/FleQ might be through FliA under a three-tiered hierarchy.

The varied functions of FliT in flagellar motility have been shown in several pathogenic bacteria. For example, FliT has been described as the filament-capping protein FliD substrate-specific chaperone in S. typhimurium [24]. Deletion of $f l i D$ inhibited the assembly of flagellin molecules onto the hooks, resulting in failure to filament biogenesis [37, 38]. However, no difference in swimming ability was observed between wildtype and the mutant [23]. In contrast, $\Delta f l i T$ showed normal flagellar filaments but attenuated swimming motility in P. fluorescens F113 [31], suggesting that FliT might not act as a FliD chaperone. Our current observation that FliT was less conserved in the strains of E. coli, S. typhimurium, P. fluorescens and Xoo (Fig. 1) implicates that FliT may function differentially in flagellar motility in various bacteria. In this study, in frame deletion of fliTX led to significantly abnormal filaments and reduced swimming motility (Fig. 3), demonstrating that FliTX plays important roles in filament assembly and motility in Xoo. Further experiments are required to determine whether FliTX functions as a FliD chaperone to affect the flagellar motility in Xoo.

The role of FliT in bacterial virulence has only been reported in S. typhimurium, in which the transcription of T3SS-containning SPI1 was induced upon disruption of $f l i T$, and the repressive effect of fliT on SPI1 genes was completely abolished in $\triangle f l h D C$ [32], indicating that FliT negatively regulates the virulence and related gene expression in the FlhDC-dependent manner in Salmonella. In this study, we demonstrated that in frame deletion of fliTX resulted in dramatically reduced lesion length and bacterial growth in rice (Fig. 4), and impaired HR-inducing ability in tobacco (Fig. 5a). It has been known that the T3SS plays critical roles in conferring pathogenicity on the host and triggering the HR on nonhost plants by delivering effector proteins into plant cells $[33,34]$. Meanwhile, in the current study, we showed that the expression of two T3SS regulator genes, $h r p G$ and $h r p X$, were attenuated in the $\triangle f l i T X$ mutant (Fig. 6). Thus, this study provides for the first time the experimental evidence that FliTX functions to promote the bacterial virulence via regulating T3SS gene expression in Xoo. Based on our previous demonstration that RpoN2 positively regulates the virulence on rice through an unknown manner [10], and the current observation that fliTX is up-regulated by $\mathrm{RpoN} 2$ and required for 

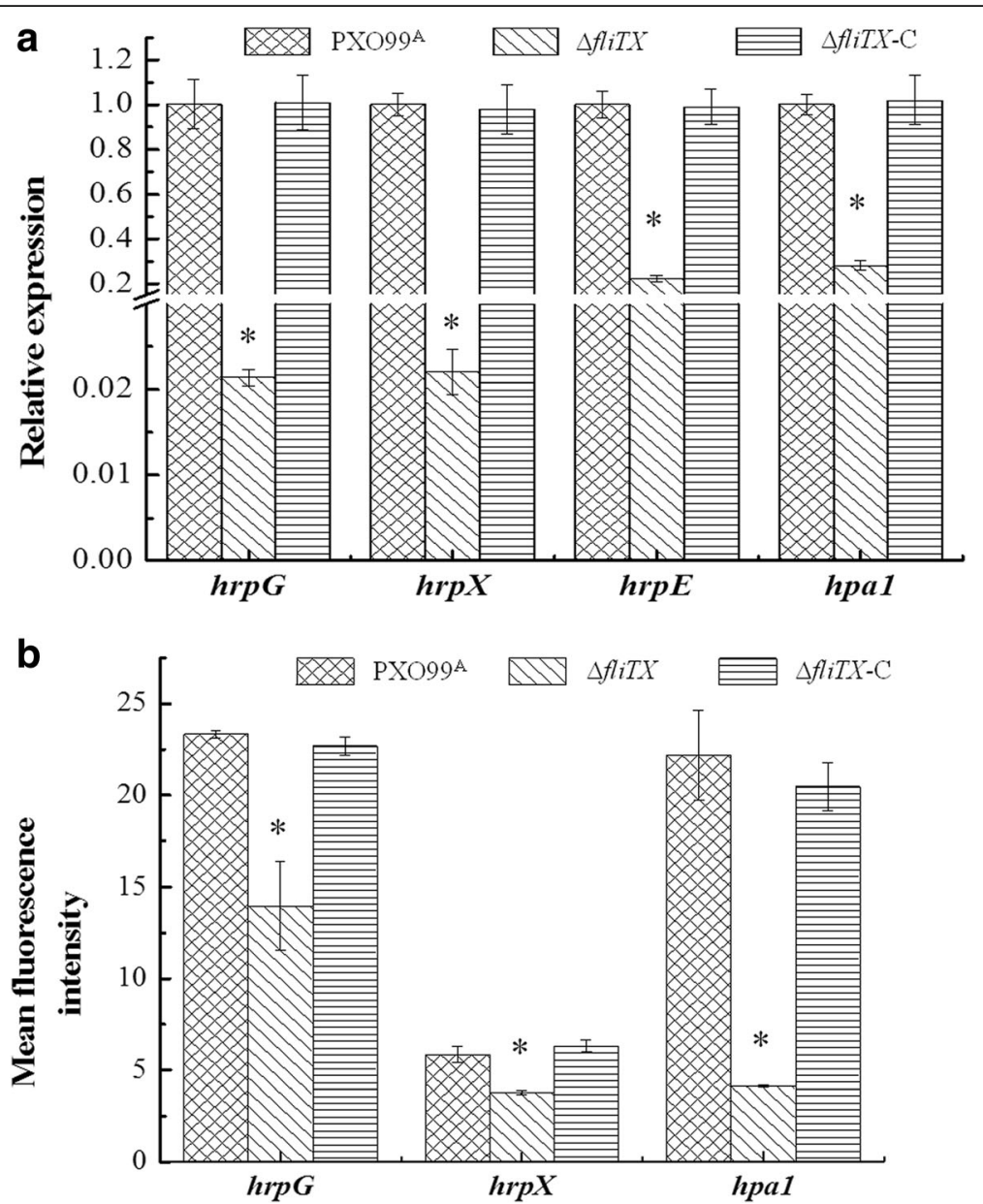

Fig. 6 Transcription of T3SS-related genes in Xanthomonas oryzae pv. oryzae strains. a The relative expression of T3SS-related genes was detected by qRT-PCR in PXO99 ${ }^{A}, \triangle f l i T X$ and $\triangle$ fliTX-C strains. Fold changes of each gene was calculated using the $2^{-\triangle \Delta C t}$ method. b Promoter activity of hrpG, hrpX and hpal in PXO99 ${ }^{A}, \triangle f l i T X$ and $\triangle$ fliTX-C strains. The promoter of hrpG, hrpX and hpal were ligated to pPROBE-AT, a broad-host-range vector carrying a promoter-less gfp gene, resulting in plasmids pPhrpG, pPhrpX and pPhpa1, respectively. These plasmids, pPhrpG, pPhrpX and pPhpa1, were transferred to fliTX deletion mutant, complementary strain and wildtype strains by electroporation. Green fluorescent protein mean fluorescence intensity was determined for gated populations of bacterial cells by flow cytometry. Error bars represent standard deviations from three biological repeats, and asterisk indicates $P<0.05$ by Student's $t$ test

the virulence in Xoo, it is reasonable to speculate that FliTX works in the RpoN2-dependent pathway to promote the bacterial pathogenesis in rice. More investigations are needed to confirm this hypothesis and further understand the regulatory mechanism of virulence by FliTX in Xoo.

For the assembly of bacterial flagellum for motility, the flagellar type III export apparatus utilizes both ATP and proton motive force to cross the cytoplasmic membrane and export flagellar proteins from the cytoplasm to the cell membrane [28]. FliT acts as the specific chaperone of the filament-capping protein FliD that is protected from degradation and aggregation in the cytoplasm and efficiently transferred to the distal end of the flagellar structure [26]. However, it remains mysterious whether and how the FliT protein is secreted. In addition, we showed that the recombinant FliTX protein induced HR in monhost tobacco leaves (Fig. 5b), implicating a potential role of FliTX in inducing plant defense responses. Therefore, it is required to further demonstrate whether and how FliTX is secreted into the plant cells during the induction of HR.

\section{Conclusions}

The fliTX gene is transcriptionally up-regulated by RpoN2/FleQ and FliA, and necessary for flagellar assembly and motility in Xoo. Deletion of fliTX led to significantly reduced virulence in rice, attenuated ability of induction of HR in tobacco and decreased hrp gene expression. RpoN2/FleQ- and FliA-regulated FliTX controls the bacterial pathogenesis via T3SS regulation with the unknown manner(s). 


\section{Methods}

\section{Bacterial strains and culture conditions}

Xanthomonas oryzae pv. oryzae wildtype strain $\mathrm{PXO} 99^{\mathrm{A}}$ and derived mutants were grown in peptone sucrose agar (PSA) medium [39] or M210 liquid medium [40] at $28{ }^{\circ} \mathrm{C}$, Escherichia coli DH5 $\alpha$ and BL21 strains were grown in Luria-Bertani (LB) medium at $37{ }^{\circ} \mathrm{C}$. The antibiotics used were ampicillin (Ap), gentamicin (Gm), kanamycin $(\mathrm{Km})$ and spectinomycin $(\mathrm{Sp})$ at concentrations of $100,50,50$, and $50 \mu \mathrm{g} / \mathrm{mL}$, respectively. The bacterial strains and plasmids used in this study are listed in Table 1.

\section{Bioinformatics analysis of fliTX}

The domain organization of FliTX was analyzed using online software available at the SMART Website (http:// smart.embl-heidelberg.de/). The amino acid sequences of FliTX were obtained from the National Center for
Biotechnology Information (NCBI) website. BLASTP was using for searching the homology in Xanthomonas species. Relevant sequence alignment was performed using the DNAMAN software (Lynnon Biosoft, San Ramon, USA).

\section{Generation of lacZ fusion and assay for $\beta$-galactosidase activity}

The promoter region ( -309 to -1$)$ of $f l i S$ was amplified from PXO99 ${ }^{\mathrm{A}}$ genomic DNA using specific primers fliSpF/R (Additional file 2: Table S1), and ligated into the HindIII and BamHI sites of the pHT304BZ vector containing a promoterless lac $Z$ reporter gene [41]. Recombinant pHTpS was verified by DNA sequencing (Beijing Genomics Institute, Beijing) and treated with HindIII and KpnI, and the fragment containing fliS promoter region and the promoterless $l a c Z$ reporter gene was obtained and then cloned into plasmid pHM1 [42]. Finally,

Table 1 Bacterial strains and plasmids used in this study

\begin{tabular}{|c|c|c|}
\hline Strain or plasmid & Relevant characteristics ${ }^{a}$ & Source or Reference \\
\hline \multicolumn{3}{|l|}{ Escherichia coli } \\
\hline $\mathrm{DH} 5 \mathrm{a}$ & supE44 $\Delta$ lacU169(Ф80lacZ $\Delta M 15)$ hsdR17 recA1 endA1 gyrA96 thi-1 relA1 & {$[49]$} \\
\hline BL21 & For protein expression & Novagen \\
\hline \multicolumn{3}{|c|}{ Xanthomonas oryzae pv. oryzae } \\
\hline PXO99 & Wildtype strain, Philippine race 6 & Lab collection \\
\hline$\triangle$ fliTX & fliTX gene deletion mutant derived from PXO99 ${ }^{\mathrm{A}}$ & This study \\
\hline$\triangle f l i T X-C$ & Complementary strain of $\triangle f l i T X, A^{r}$ & This study \\
\hline$\triangle r p o N 2$ & rpoN2 gene deletion mutant derived from $\mathrm{PXO99}{ }^{\mathrm{A}}, \mathrm{Gm}^{\mathrm{r}}$ & Our lab \\
\hline$\Delta r p o N 2-C$ & Complementary strain of $\Delta r p o N 2, A^{r}$ & Our lab \\
\hline$\triangle$ fleQ & fleQ gene deletion mutant derived from PXO99 ${ }^{\mathrm{A}}, \mathrm{Gm}^{\mathrm{r}}$ & Our lab \\
\hline$\triangle f l e Q-C$ & Complementary strain of $\Delta f l e Q, A p^{r}$ & Our lab \\
\hline$\triangle$ fliA & fliA gene deletion mutant derived from PXO99 ${ }^{A}, \mathrm{Gm}^{\mathrm{r}}$ & Our lab \\
\hline$\triangle$ fliA-C & Complementary strain of $\triangle$ fliA, $A p^{r}$ & Our lab \\
\hline \multicolumn{3}{|l|}{ Plasmid } \\
\hline pMD18-T & Cloning vector, $\mathrm{Ap}^{r}$ & TaKaRa, Tokyo \\
\hline pKMS1 & Suicidal vector carrying $s a c B$ gene for non-marker mutagenesis, $\mathrm{Km}^{\mathrm{r}}$ & {$[45]$} \\
\hline pBBR1MCS-4 & Broad-host range expression vector, $\mathrm{Ap}^{\mathrm{r}}$ & {$[50]$} \\
\hline pHT304BZ & Promoterless lacZ vector, $\mathrm{Ap}^{\mathrm{r}}$ & {$[41]$} \\
\hline pHTpS & pHT304BZ derivative carrying the promoter region of fliS, $\mathrm{Ap}^{\mathrm{r}}$ & This study \\
\hline pHM1 & Broad-host range expression vector, $\mathrm{Sp}^{\mathrm{r}}$ & {$[42]$} \\
\hline pH-flisp-lacZ & pHM1 derivative carrying the promoter region of flis and promoterless lacZ, Sp ${ }^{r}$ & This study \\
\hline pET-28a & 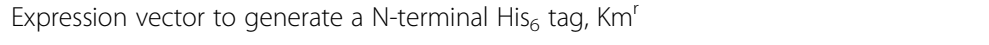 & Haigene \\
\hline pET-fliTX & pET-28a derivative carrying fliTX, $\mathrm{Km}^{\mathrm{r}}$ & This study \\
\hline PPROBE-AT & broad-host-range vector carrying a promoter-less gfp gene, $\mathrm{Ap}^{\mathrm{r}}$ & {$[47]$} \\
\hline pPhrpG & pPROBE-AT derivative carrying the promoter region of $h r p G$ and promoterless $g f p, A^{r}$ & This study \\
\hline pPhrpX & pPROBE-AT derivative carrying the promoter region of $h r p X$ and promoterless $g f p, \mathrm{Ap}^{r}$ & This study \\
\hline pPhpa1 & pPROBE-AT derivative carrying the promoter region of hpal and promoterless $g f p, A^{r}$ & Our lab \\
\hline
\end{tabular}

${ }^{a} \mathrm{Ap}^{r}, \mathrm{Km}^{\mathrm{r}}, \mathrm{Sp}^{\mathrm{r}}$, and $\mathrm{Gm}^{\mathrm{r}}$ indicate resistant to ampicillin, kanamycin, spectinomycin and gentamicin, respectively 
the recombinant plasmid $\mathrm{pH}-f l i S p-l a c Z$ was generated and introduced into PXO99 ${ }^{\mathrm{A}}$ and derived mutants. The resultant strains contained $\mathrm{pH}$-fliSp-lacZ were selected by resistance to spectinomycin and verified by polymerase chain reaction (PCR). For $\beta$-galactosidase assay, these Xoo strains were cultured in M210 liquid medium at $28{ }^{\circ} \mathrm{C}$ and $200 \mathrm{rpm}$, and till an optical density $\left(\mathrm{OD}_{600}\right)$ of 1.0 , cells were collected by centrifugation at $12,000 \mathrm{~g}$. The $\beta$-galactosidase activity was determined using the $\beta$ Galactosidase Enzyme Assay System (Promega, Wisconsin, USA). The experiments were repeated three times, independently.

\section{RNA isolation and qRT-PCR analysis}

RNA isolation and qRT-PCR analysis were performed as described previously with some modifications [8]. Briefly, Xoo strains were grown in M210 liquid medium at $28{ }^{\circ} \mathrm{C}$ till $\mathrm{OD}_{600}$ of 0.8 , and harvested by centrifugation at 12,000 $\mathrm{g}$ for analysis of gene expression. For T3SS-related gene assays, the harvested bacterial cells were sub-cultured in XOM2 medium [43] overnight at $28{ }^{\circ} \mathrm{C}$ and collected again. Total RNA was extracted with RNAprep pure Cell/Bacteria Kit (Tiangen, Beijing, China) and treated with DNase and cDNA was synthesized from total RNA using the FastQuant RT Super Mix (Tiangen, Beijing, China). RT-qPCR was performed using Quant qRT-PCR kit (Tiangen, Beijing, China) in Applied Biosystem's 7500 (Applied Biosystems, Foster City, CA, USA) with gene specific primers, and $\operatorname{gyr} B$ was used as a reference gene (Additional file 2: Table S1). The relative expression ratio was calculated using $2^{-\Delta \Delta \mathrm{Ct}}$ method [44]. These experiments were performed in three biological replicates and triplicate PCR.

\section{Protein expression and purification}

The FliTX expression and purification were performed as described previously [8]. Briefly, the coding region for fliTX was amplified by PCR with primers TXF/R (Additional file 2: Table S1) and ligated to the middle vector pMD18-T for verification by DNA sequencing. Then the fliTX fragment was digested from verified pMD18-T with corresponding restriction enzymes and ligated to pET28a, resulting in pET-fliTX. The recombinant plasmid was transformed into E. coli BL21 strain for protein expression. For protein purification, the BL21 strain carrying pET-fliTX was cultured in LB liquid medium at $37{ }^{\circ} \mathrm{C}$ to $\mathrm{OD}_{600}$ of 0.6 , and isopropyl-thiogalactopyranoside at a final concentration of $0.1 \mathrm{mM}$ was added to induce fliTX expression. After $6 \mathrm{~h}$ cultured, the BL21 cells were collected by centrifugation and re-suspended in $0.1 \times$ PBS. The crude cell extracts were obtained by sonication and centrifuged at 12,000 $\mathrm{g}$ for $10 \mathrm{~min}$ in $4{ }^{\circ} \mathrm{C}$. The supernatant containing the soluble proteins was mixed with pre-equilibrated Ni2_resin
(GE Healthcare, Piscataway, NJ, USA) for $1 \mathrm{~h}$ at $4{ }^{\circ} \mathrm{C}$. Finally, the FliTX protein combined to $\mathrm{Ni}$ was eluted with elution buffer $(20 \mathrm{mM}$ Tris- $\mathrm{HCl}, 350 \mathrm{mM} \mathrm{NaCl}, 0.5 \mathrm{mM}$ EDTA, $10 \%$ glycerol, $5 \mathrm{mM} \mathrm{MgCl}_{2}$ and $100 \mathrm{mM}$ imidazole, $\mathrm{pH}$ 8.0) and dialyzed with $0.1 \times$ PBS. The purified FliTX was detected by sodium dodecyl sulfate polyacrylamide gel electrophoresis (SDS-PAGE) and adjusted to $10 \mu \mathrm{M}$ with $0.1 \times \mathrm{PBS}$ for the next experiments.

\section{Gene deletion and complementation}

An in-frame gene deletion mutant $\triangle f l i T X$ derived from PXO99 $^{\mathrm{A}}$ was constructed through homologous recombination by using the suicide vector pKMS1 [45]. About $900 \mathrm{bp}$ upstream and $800 \mathrm{bp}$ downstream fragments of the fliTX gene were amplified by PCR from Xoo genomic DNA using primers fliTXLF/R and fliTXRF/R, respectively. The PCR products were first cloned into the middle vector pMD18-T (Takara, Dalian, China) and verified by sequencing. Then the upstream and downstream fragments of fliTX were digested with corresponding restriction enzymes from the middle vectors and ligated into pKMS1. The final vector pKMS1 containing upstream and downstream fragments of fliTX was introduced into Xoo by electroporation. The transformants were first selected on NAN medium ( $1 \%$ tryptone, $0.1 \%$ yeast extract, $0.3 \%$ peptone and $1.5 \%$ agar) with $\mathrm{Km}$, and after continuous transfer cultured in NBN medium (1\% tryptone, $0.1 \%$ yeast extract and $0.3 \%$ peptone) at least five times. Finally, the $\triangle f l i T X$ mutant was selected on NAS medium (1\% tryptone, $0.1 \%$ yeast extract, $0.3 \%$ peptone, $10 \%$ sucrose and $1.5 \%$ agar) and further confirmed by PCR analysis. For complementation strain construction, the full length of fliTX was amplified by PCR with primers fliTXF/R and inserted into vector $\mathrm{pMD} 18-\mathrm{T}$. After verifying by sequencing, $f l i T X$ was digested from pMD18-T and ligated into pBBR1MCS-4. The final vector pBBR1MCS-4 containing fliTX was electroporated into $\triangle f l i T X$ and confirmed by PCR analysis, resulting in the $\triangle f l i T X$ complementary strain $(\triangle f l i T X-C)$. The primers are listed in Additional file 2: Table S1.

\section{Motility assay and electron microscopy visualization of filament}

For motility assay, bacterial strains were cultured in M210 liquid medium till reached $\mathrm{OD}_{600}$ of 1.0 and harvested by centrifugation at $12,000 \mathrm{~g}$ for $5 \mathrm{~min}$. Cells were re-suspended in equal volume of $\mathrm{dd}_{2} \mathrm{O}$. Two microliters of bacterial suspension were spotted onto semisolid plates $(0.03 \%$ peptone, $0.03 \%$ yeast extract and $0.25 \%$ agar) and incubated at $28{ }^{\circ} \mathrm{C}$. The diameters of the swimming zone were recorded after 4 days. The experiments were repeated three times with five replicates for each time. The TEM assay was performed as described previously [46]. Briefly, bacterial strains were grown on PSA plates at $28{ }^{\circ} \mathrm{C}$ for $48 \mathrm{~h}$, and cells were collected 
and re-suspended with $\mathrm{ddH}_{2} \mathrm{O}$, then one drop of suspension was deposited onto grids coated with Formvar (Standard Technology, Ormond Beach, FL, USA). The grids with bacteria were stained with $2 \%$ uranyl acetate for $30 \mathrm{~s}$, and air drying for $10 \mathrm{~min}$. The bacterial flagella were observed by TEM using Hitachi H-7500 electron microscope.

\section{Pathogenicity test}

As described above, bacterial strains were cultured in M210 liquid medium at $28{ }^{\circ} \mathrm{C}$ and $200 \mathrm{rpm}$ till reached $\mathrm{OD}_{600}$ of 1.0, and collected by centrifugation at $12,000 \mathrm{~g}$ for $5 \mathrm{~min}$, and re-suspended with equal volume of $\mathrm{dd}_{2} \mathrm{O}$. For the disease lesion length assay, bacterial cells were inoculated into leaves of 8-week-old rice (Oryza sativa ssp. indica) cultivar IR24 using the leaf-clipping method [8], and the lesion length was measured at 14 days postinoculation. For the bacterial population assay, the top $20 \mathrm{~cm}$ of inoculated rice leaves were collected and weighted, then ground into $1 \mathrm{~mL}$ of $d_{d d} \mathrm{H}_{2} \mathrm{O}$. The ground mixtures were optional diluted and spread onto the PSA plates. The bacterial colonies were counted after cultured in incubator with $28{ }^{\circ} \mathrm{C}$ for $72 \mathrm{~h}$. At least 10 leaves were inoculated for each strain, and the experiments were repeated three times, independently.

\section{Assay for induction of HR in tobacco}

Xoo strains were grown in M210 liquid medium at $28^{\circ}$ $\mathrm{C}$ to $\mathrm{OD}_{600}$ of 1.0 , and collected by centrifugation at $7000 \mathrm{~g}$ for $10 \mathrm{~min}$. The cells were re-suspended with $\mathrm{dd}_{2} \mathrm{O}$, and adjusted to $\mathrm{OD}_{600}$ of 0.1. Then these bacterial cells or purified FliTX protein were inoculated into leaves of 6-week-old tobacco (Nicotiana benthamiana) using a needleless syringe. The HR symptoms were detected and photographed at $24 \mathrm{~h}$ post-inoculation. The experiments were repeated three times, independently.

\section{Flow cytometry detection}

The plasmid pPhpal containing the hpal promoter region and a promoterless $g f p$ gene was constructed in our previous studies [40]. Here two near 200-bp fragments containing the promoter region of $h r p G$ or $h r p X$ were PCR amplified using the primers hrpGpF/R or hrpXpF/ $\mathrm{R}$ (Additional file 2: Table S1), and ligated to pPROBEAT, a broad-host-range vector carrying a promoter-less $g f p$ gene [47], resulting in plasmids $\mathrm{pPhrpG}$ and $\mathrm{pPhrpX}$, respectively. These plasmids, pPhpa1, pPhrpG and pPhrpX, were transferred to fliTX deletion mutant, complementary strain and wildtype strains by electroporation. The transformed strains were cultured in M210 liquid medium to $\mathrm{OD}_{600}$ of 1.0 and transferred to XOM2 medium for $12 \mathrm{~h}$ at $28{ }^{\circ} \mathrm{C}$. The cells were collected by centrifugation at $12,000 \mathrm{~g}$ for $5 \mathrm{~min}$ and resuspended with $0.1 \times$ PBS. The promoter activities of hpal, hrpG and hrpX were detected using a FACSCaliber flow cytometer (BD Bioscience, CA, USA) as previously described [48]. Xoo wildtype carrying a promoterless pBROBE-AT was used as a negative control. The experiments were repeated three times, independently.

\section{Data analysis}

The values of $\beta$-galactosidase activity, gene expression level, motility zone, disease lesion length and bacterial population were presented as means \pm SD (standard deviations). Student's $t$ test was performed with statistical significance set at the 0.05 confidence level.

\section{Additional files}

Additional file 1: Figure S1. Coomassie blue staining of the FliTX protein expressed and extracted from E. coli strain BL21. M: Molecular marker; 1: FliTX in the soluble fraction; 2: purified FliTX; 3: FliTX in the insoluble fraction. (TIFF $424 \mathrm{~kb}$ )

Additional file 2: Table S1. The primers used in this study. (DOCX $17 \mathrm{~kb}$ )

\section{Abbreviations}

Ap: Ampicillin; $\mathrm{dd}_{2} \mathrm{O}$ : Sterilized double-distilled water;

EPS: Exopolysaccharide; Gm: Gentamicin; HR: Hypersensitive response; Km: Kanamycin; LB: Luria-Bertani; NCBI: National Center for Biotechnology Information; $\mathrm{OD}_{600}$ : Optical density; PCR: Polymerase chain reaction; PSA: Peptone sucrose agar; qRT-PCR: Quantitative real-time polymerase chain reaction; RT-PCR: Reverse transcription polymerase chain reaction;

SD: Standard deviations; SDS-PAGE: Sodium dodecyl sulfate polyacrylamide gel electrophoresis; Sp: Spectinomycin; SPI1: Salmonella pathogenicity island 1; T3SS: Type III secretion system; TEM: Transmission electron microscope; Xoo: Xanthomonas oryzae pv. oryzae

\section{Acknowledgements}

We would like to thank John J. Srok at University of Wisconsin-Milwaukee for editing the language.

\section{Funding}

This work was supported by the grants from the National Basic Research Program of China (2011CB100700) and the Nature Science Foundation of China (31600105).

Availability of data and materials

All data generated or analyzed during this study are included in this published article and its Additional files 1 and 2 .

\section{Authors' contributions}

$\mathrm{CY}$ and $\mathrm{CYH}$ designed the experiments; $\mathrm{CY}$ performed the experiments; $\mathrm{CY}$, $\mathrm{HMC}, \mathrm{FT}, \mathrm{FHY}$ and $\mathrm{CYH}$ analyzed the data; $\mathrm{CY}, \mathrm{FT}$ and $\mathrm{CYH}$ wrote the manuscript; All authors read and approved the final manuscript.

Ethics approval and consent to participate Not applicable

Consent for publication

Not applicable

Competing interests

The authors declare that they have no competing interests.

\section{Publisher's Note}

Springer Nature remains neutral with regard to jurisdictional claims in published maps and institutional affiliations. 
Received: 9 May 2017 Accepted: 2 August 2017 Published online: 09 August 2017

\section{References}

1. Nino-Liu DO, Ronald PC, Bogdanove AJ. Xanthomonas oryzae pathovars: model pathogens of a model crop. Mol Plant Pathol. 2006;7(5):303-24

2. Martin GB, Bogdanove AJ, Sessa G. Understanding the functions of plant disease resistance proteins. Annu Rev Plant Biol. 2003;54:23-61.

3. Ronald PC. The molecular basis of disease resistance in rice. Plant Mol Biol. 1997;35(1-2):179-86

4. Das A, Rangaraj N, Sonti RV. Multiple adhesin-like functions of Xanthomonas oryzae pv. oryzae are involved in promoting leaf attachment, entry, and virulence on rice. Mol Plant-Microbe Interact. 2009;22(1):73-85.

5. White FF, Yang B. Host and pathogen factors controlling the riceXanthomonas oryzae interaction. Plant Physiol. 2009;150(4):1677-86.

6. Tsuge S, Terashima S, Furutani A, Ochiai H, Oku T, Tsuno K, Kaku H, Kubo Y. Effects on promoter activity of base substitutions in the cis-acting regulatory element of HrpXo regulons in Xanthomonas oryzae pv. oryzae. J. Bacteriol. 2005;187(7):2308-14.

7. He YW, Wu J, Cha JS, Zhang LH. Rice bacterial blight pathogen Xanthomonas oryzae pv. oryzae produces multiple DSF-family signals in regulation of virulence factor production. BMC Microbiol. 2010;10:187.

8. Yang FH, Tian F, Sun L, Chen HM, Wu MS, Yang CH, He CY. A novel twocomponent system PdeK/PdeR regulates c-di-GMP turnover and virulence of Xanthomonas oryzae pv. oryzae. Mol Plant-Microbe Interact. 2012;25(10):1361-9.

9. Salzberg SL, Sommer DD, Schatz MC, Phillippy AM, Rabinowicz PD, Tsuge S, Furutani A, Ochiai H, Delcher AL, Kelley D, et al. Genome sequence and rapid evolution of the rice pathogen Xanthomonas oryzae pv. oryzae PXO99 A. BMC Genomics. 2008:9:204.

10. Tian F, Yu C, Li HY, Wu XL, Li B, Chen HM, Wu MS, He CY. Alternative sigma factor RpoN2 is required for flagellar motility and full virulence of Xanthomonas oryzae pv. oryzae. Microbiol Res. 2015;170:177-83.

11. Haefele DM, Lindow SE. Flagellar motility confers epiphytic fitness advantages upon Pseudomonas syringae. Appl Environ Microbiol. 1987; 53(10):2528-33.

12. Giron JA, Torres AG, Freer E, Kaper JB. The flagella of enteropathogenic Escherichia coli mediate adherence to epithelial cells. Mol Microbiol. 2002; 44(2):361-79.

13. Tans-Kersten J, Brown D, Allen C. Swimming motility, a virulence trait of Ralstonia solanacearum, is regulated by FlhDC and the plant host environment. Mol Plant-Microbe Interact. 2004;17(6):686-95.

14. Aldridge P, Hughes KT. Regulation of flagellar assembly. Curr Opin Microbiol. 2002;5(2):160-5.

15. Kutsukake $K$, Ohya $Y$, lino $T$. Transcriptional analysis of the flagellar regulon of Salmonella typhimurium. J Bacteriol. 1990;172(2):741-7.

16. Macnab RM. Type III flagellar protein export and flagellar assembly. Biochim Biophys Acta. 2004;1694(1-3):207-17.

17. Liu X, Matsumura P. The FlhD/FlhC complex, a transcriptional activator of the Escherichia coli flagellar class II operons. J Bacteriol. 1994;176(23):7345-51.

18. Karlinsey JE, Tanaka S, Bettenworth V, Yamaguchi S, Boos W, Aizawa SI, Hughes KT. Completion of the hook-basal body complex of the Salmonella typhimurium flagellum is coupled to FlgM secretion and fliC transcription. Mol Microbiol. 2000;37(5):1220-31.

19. Sorenson MK, Ray SS, Darst SA. Crystal structure of the flagellar sigma/antisigma complex sigma(28)/FlgM reveals an intact sigma factor in an inactive conformation. Mol Cell. 2004;14(1):127-38

20. Dasgupta N, Wolfgang MC, Goodman AL, Arora SK, Jyot J, Lory S, Ramphal R. A four-tiered transcriptional regulatory circuit controls flagellar biogenesis in Pseudomonas aeruginosa. Mol Microbiol. 2003:50(3):809-24.

21. McCarter LL. Regulation of flagella. Curr Opin Microbiol. 2006;9(2):180-6.

22. Bange G, Kummerer N, Engel C, Bozkurt G, Wild K, Sinning I. FlhA provides the adaptor for coordinated delivery of late flagella building blocks to the type III secretion system. Proc Natl Acad Sci U S A. 2010;107(25):11295-300.

23. Bennett JC, Thomas J, Fraser GM, Hughes C. Substrate complexes and domain organization of the Salmonella flagellar export chaperones FlgN and FliT. Mol Microbiol. 2001:39(3):781-91.

24. Fraser GM, Bennett JC, Hughes C. Substrate-specific binding of hookassociated proteins by FlgN and FliT, putative chaperones for flagellum assembly. Mol Microbiol. 1999;32(3):569-80.

25. Imada K, Minamino T, Kinoshita M, Furukawa Y, Namba K. Structural insight into the regulatory mechanisms of interactions of the flagellar type III chaperone FliT with its binding partners. Proc Natl Acad Sci U S A. 2010; 107(19):8812-7.

26. Minamino T, Kinoshita M, Imada K, Namba K. Interaction between Flil ATPase and a flagellar chaperone FliT during bacterial flagellar protein export. Mol Microbiol. 2012;83(1):168-78.

27. Yamamoto S, Kutsukake K. FliT acts as an anti-FlhD2C2 factor in the transcriptional control of the flagellar regulon in Salmonella enterica serovar typhimurium. J Bacteriol. 2006;188(18):6703-8.

28. Minamino T. Protein export through the bacterial flagellar type III export pathway. Biochim Biophys Acta. 2014;1843(8):1642-8.

29. Khanra N, Rossi P, Economou A, Kalodimos CG. Recognition and targeting mechanisms by chaperones in flagellum assembly and operation. Proc Natl Acad Sci U S A. 2016:113(35):9798-803.

30. Sato Y, Takaya A, Mouslim C, Hughes KT, Yamamoto T. FliT selectively enhances proteolysis of FlhC subunit in FlhD4C2 complex by an ATPdependent protease, ClpXP. J Biol Chem. 2014;289(47):33001-11.

31. Capdevila S, Martinez-Granero FM, Sanchez-Contreras M, Rivilla R, Martin M. Analysis of Pseudomonas fluorescens F113 genes implicated in flagellar filament synthesis and their role in competitive root colonization. Microbiology. 2004;150(Pt 11):3889-97.

32. Hung CC, Haines $L$, Altier $C$. The flagellar regulator fliT represses Salmonella pathogenicity island 1 through flhDC and fliZ. PLoS One. 2012;7(3):e34220.

33. Alfano JR, Collmer A. The type III (Hrp) secretion pathway of plant pathogenic bacteria: trafficking harpins, Avr proteins, and death. J Bacteriol. 1997;179(18):5655-62

34. Buttner D, Bonas U. Common infection strategies of plant and animal pathogenic bacteria. Curr Opin Plant Biol. 2003;6(4):312-9.

35. Wengelnik K, Van den Ackerveken G, Bonas U. HrpG, a key hrp regulatory protein of Xanthomonas campestris pv. vesicatoria is homologous to twocomponent response regulators. Mol Plant-Microbe Interact. 1996;9(8):704-12.

36. Kutsukake K, Ide N. Transcriptional analysis of the flgK and fliD operons of Salmonella typhimurium which encode flagellar hook-associated proteins. Mol Gen Genet. 1995;247(3):275-81

37. Yokoseki T, Kutsukake $K$, Ohnishi $K$, lino T. Functional analysis of the flagellar genes in the fliD operon of Salmonella typhimurium. Microbiology. 1995; 141(Pt 7):1715-22.

38. Homma M, Kutsukake K, lino T, Yamaguchi S. Hook-associated proteins essential for flagellar filament formation in Salmonella typhimurium. J Bacteriol. 1984;157(1):100-8.

39. Tsuchiya K, Mew TW, Wakimoto S. Bacteriological and pathological characteristics of wild type and induced mutants of Xanthomonas campestris pv. oryzae. Phytopathology. 1982;72:43-6.

40. Fan SS, Tian F, Li JY, Hutchins W, Chen HM, Yang FH, Yuan X, Cui ZN, Yang $\mathrm{CH}, \mathrm{He} \mathrm{CY}$. Identification of phenolic compounds that suppress the virulence of Xanthomonas oryzae on rice via the type III secretion system. Mol Plant Pathol. 2016; doi:10.1111/mpp.12415.

41. Lereclus D, Agaisse $H$, Gominet M, Salamitou S, Sanchis V. Identification of a Bacillus thuringiensis gene that positively regulates transcription of the phosphatidylinositol-specific phospholipase $\mathrm{C}$ gene at the onset of the stationary phase. J Bacteriol. 1996;178(10):2749-56.

42. Hopkins CM, White FF, Choi SH, Guo A, Leach JE. Identification of a family of avirulence genes from Xanthomonas oryzae pv. oryzae. Mol Plant-Microbe Interact. 1992:5(6):451-9.

43. Tsuge S, Furutani A, Fukunaka R, Oku T, Tsuno K, Ochiai H, Inoue Y, Kaku H, Kubo Y. Expression of Xanthomonas oryzae pv. oryzae hrp genes in XOM2, a novel synthetic medium. J Gen Plant Pathol. 2002;68(4):363-71.

44. Livak KJ, Schmittgen TD. Analysis of relative gene expression data using real-time quantitative PCR and the 2(T)(-Delta Delta C) method. Methods. 2001;25(4):402-8.

45. Li YR, Zou HS, Che YZ, Cui YP, Guo W, Zou LF, Chatterjee S, Biddle EM, Yang $\mathrm{CH}$, Chen GY. A novel regulatory role of HrpD6 in regulating hrp-hrc-hpa genes in Xanthomonas oryzae pv. oryzicola. Mol Plant-Microbe Interact. 2011;24(9):1086-101

46. Li HY, Yu C, Chen HM, Tian F, He CY. PXO 00987, a putative acetyltransferase, is required for flagellin glycosylation, and regulates flagellar motility, exopolysaccharide production, and biofilm formation in Xanthomonas oryzae pv. oryzae. Microb Pathog. 2015;85:50-7.

47. Miller WG, Leveau JH, Lindow SE. Improved gfp and inaZ broad-host-range promoter-probe vectors. Mol Plant-Microbe Interact. 2000;13(11):1243-50.

48. Yamazaki A Li J, Zeng Q Khokhani D, Hutchins WC, Yost AC, Biddle E, Toone EJ, Chen X, Yang CH. Derivatives of plant phenolic compound affect 
the type III secretion system of Pseudomonas aeruginosa via a GacS-GacA two-component signal transduction system. Antimicrob Agents Chemother. 2012;56(1):36-43.

49. Hanahan D. Studies on transformation of Escherichia coli with plasmids.J Mol Biol. 1983;166:557-80.

50. Kovach ME, Elzer PH, Hill DS, Robertson GT, Farris MA, Roop RM 2nd, Peterson KM. Four new derivatives of the broad-host-range cloning vector pBBR1MCS, carrying different antibiotic-resistance cassettes. Gene. 1995;166:175-6.

Submit your next manuscript to BioMed Central and we will help you at every step:

- We accept pre-submission inquiries

- Our selector tool helps you to find the most relevant journal

- We provide round the clock customer support

- Convenient online submission

- Thorough peer review

- Inclusion in PubMed and all major indexing services

- Maximum visibility for your research

Submit your manuscript at www.biomedcentral.com/submit 